\title{
POSSIBILITY OF OFFSHORE DISCHARGE OF NOURISHMENT SAND IN TERMS OF SAND VOLUME AND GRAIN SIZE COMPOSITION
}

\author{
Toshinori Ishikawa ${ }^{1}$, Takaaki Uda ${ }^{1}$, Toshiro San-nami ${ }^{2}$, \\ Jun-ichi Hosokawa ${ }^{3}$ and Tetsuyuki Tako
}

\begin{abstract}
On the Shonan coast facing Sagami Bay, part of the nourishment sand was considered to be transported offshore, devaluing the effect of beach nourishment. Beach changes after the beach nourishment were investigated using the Narrow Multi-Beam survey data, which have been collected since 2002. Analysis of the sand volume and grain size composition in the subareas showed that the effect of the beach nourishment on the deposition of fine sediment in the offshore zone was negligible, and that the fine material in the offshore zone was mainly brought from the erosion of the river mouth terrace.

Keywords: Chigasaki fishing port; NMB survey; beach nourishment; longshore sand transport; grain size composition
\end{abstract}

\section{INTRODUCTION}

On the Shonan coast facing Sagami Bay, Japan, the beach has been eroded owing to the rapid decrease in sand supply from the Sagami River, the primary source of sediment, after the construction of the Sagami Dam, and the riverbed mining to obtain aggregates. Furthermore, the Chigasaki fishing port breakwater was extended on the coast, which obstructed eastward longshore sand transport, resulting in downcoast erosion. As a measure against beach erosion, beach nourishment using materials composed of sand of different grain sizes and dredged from the reservoir upstream of the dam has been carried out since 2005 at the Yanagishima and Chigasaki-naka areas east of the river mouth (Ishikawa et al. 2009; 2013). Since the Chigasaki fishing port is located downcoast of the nourishment area, nourishment sand carried by prevailing eastward longshore sand transport was blocked by breakwaters, resulting in shoreline advance upcoast. Apart from the sand deposition near the shoreline, part of the nourishment sand was considered to be transported offshore, devaluing the effect of beach nourishment In addition, local fishermen feared the damage to the offshore fishing ground rich in kelp and abalone owing to the coverage of the exposed rocks by fine material. In this study, therefore, beach changes after the beach nourishment were investigated using the Narrow Multi-Beam (NMB) survey data, which have been collected once a year since 2002, taking the coast of $5 \mathrm{~km}$ stretch between the Sagami River mouth and the Chigasaki coast as an example (Fig. 1). Moreover, the grain size composition of the seabed material was analyzed.

\section{METHOD OF FIELD OBSERVATION}

In this area, eastward longshore sand transport prevails, and the Sagami River is the source of littoral sand to this coast. East of the river mouth, various coastal facilities, such as the wavedissipating works at the Yanagishima area, Chigasaki fishing port, and Chigasaki artificial headland (HL), were constructed before 1996, together with the construction of the Hiratsuka new fishing port immediately west of the river mouth. In this study, the topographic changes between 2002 and 2015 relative to the bathymetry in 2002 were analyzed on the basis of the NMB survey data, as shown Fig. 1. As shown in Fig. 1(a), an opening of $55 \mathrm{~m}$ width had been left between the offshore and the west breakwaters of the Chigasaki fishing port until 2002, and then this opening was closed by 2003. In the analysis of beach changes, therefore, 2002 was adopted as the reference year.

To investigate the grain size composition of the seabed material, the samples of the seabed material were collected on July 5, 2016 at Sts. 1-4 with water depths of 9, 12, 15, and $22 \mathrm{~m}$, respectively, offshore of the Chigasaki fishing port, and along transect Nos. 3 and 5 in January 2016 west of the Chigasaki fishing port (Fig. 1).

\footnotetext{
${ }^{1}$ Public Works Research Center, 1-6-4 Taito, Taito, Tokyo 110-0016, Japan

${ }^{2}$ Coastal Engineering Laboratory Co., Ltd., 1-22-301 Wakaba, Shinjuku, Tokyo 160-0011, Japan

${ }^{3}$ Kanagawa Prefectural Government, 1-7 Shiomi-dai, Chigasaki, Kanagawa 253-0033, Japan
} 

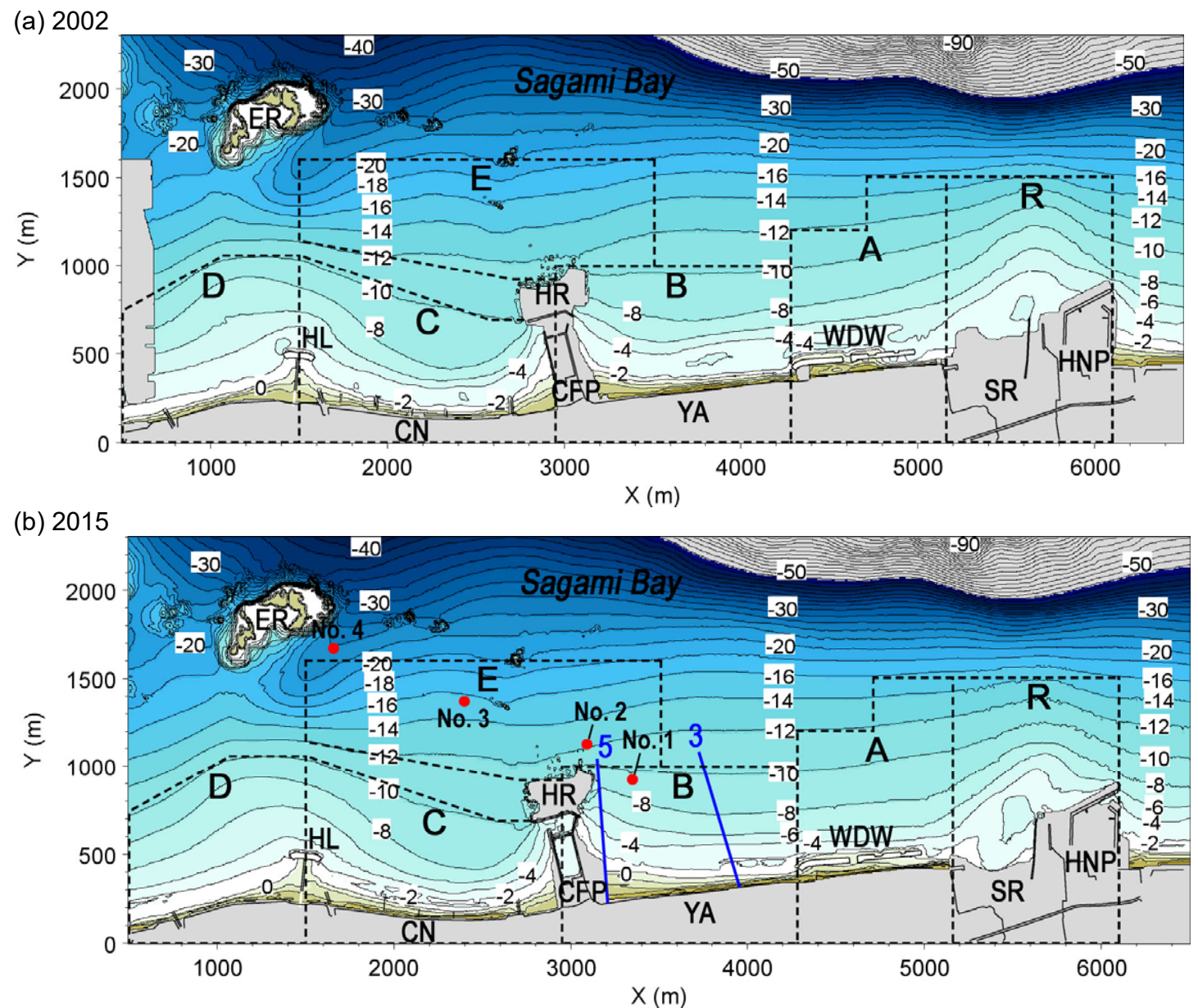

ER: Eboshi Rock, CFP: Chigasaki fishing port, SR: Sagami River, HNP: Hiratsuka New Port, HL: Chigasaki artificial headland, WDW: Wave dissipating works, HR: Hirashima Rocks, YA: Yanagishima area, CN: Chigasaki-naka area

Figure 1. Bathymetries of study area measured in 2002 and 2015.

\section{BEACH NOURISHMENT}

In the beach nourishment in the Yanagishima area, sand was supplied from a sand mound of $200 \mathrm{~m}$ length alongshore produced on the backshore, east of the wave-dissipating works, as shown in Fig. 2. The total volume of sand supplied by beach nourishment was $9.4 \times 10^{4} \mathrm{~m}^{3}$ between 2002 and 2015 at a rate of $8.0 \times 10^{3} \mathrm{~m}^{3} / \mathrm{yr}$ between 2006 and 2015 (Fig. 3). Because eastward longshore sand transport has been blocked at the Chigasaki fishing port located $1 \mathrm{~km}$ east of the Yanagishima area, sand deposited upcoast of the fishing port was used as the material for downcoast beach nourishment at a rate of $3.0 \times 10^{3} \mathrm{~m}^{3} / \mathrm{yr}$, resulting in the rate of net increase in sand volume of $5.0 \times 10^{3} \mathrm{~m}^{3} / \mathrm{yr}$ in this area. In this beach nourishment, a material with mixed grain sizes composed of sand and gravel was employed, as shown in Fig. 4. The grain size composition of the material was $43.4 \%$ gravel, $13.0 \%$ coarse sand, $19.8 \%$ medium-size sand, $15.8 \%$ fine sand, and $8 \%$ silt on average (Fig. 5 ). 


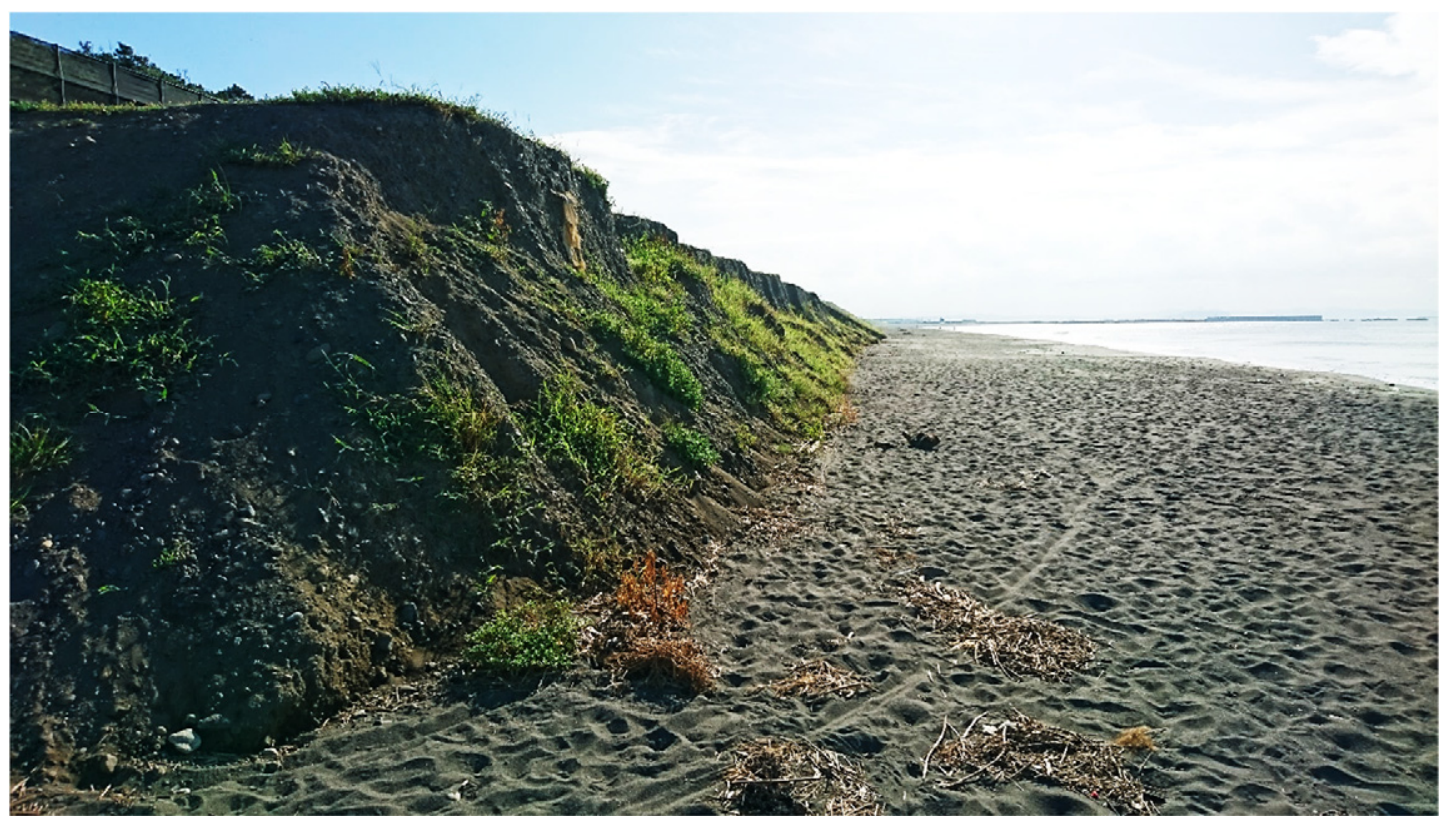

Figure 2. Sand mound for beach nourishment in Yanagishima area (August 16, 2016).

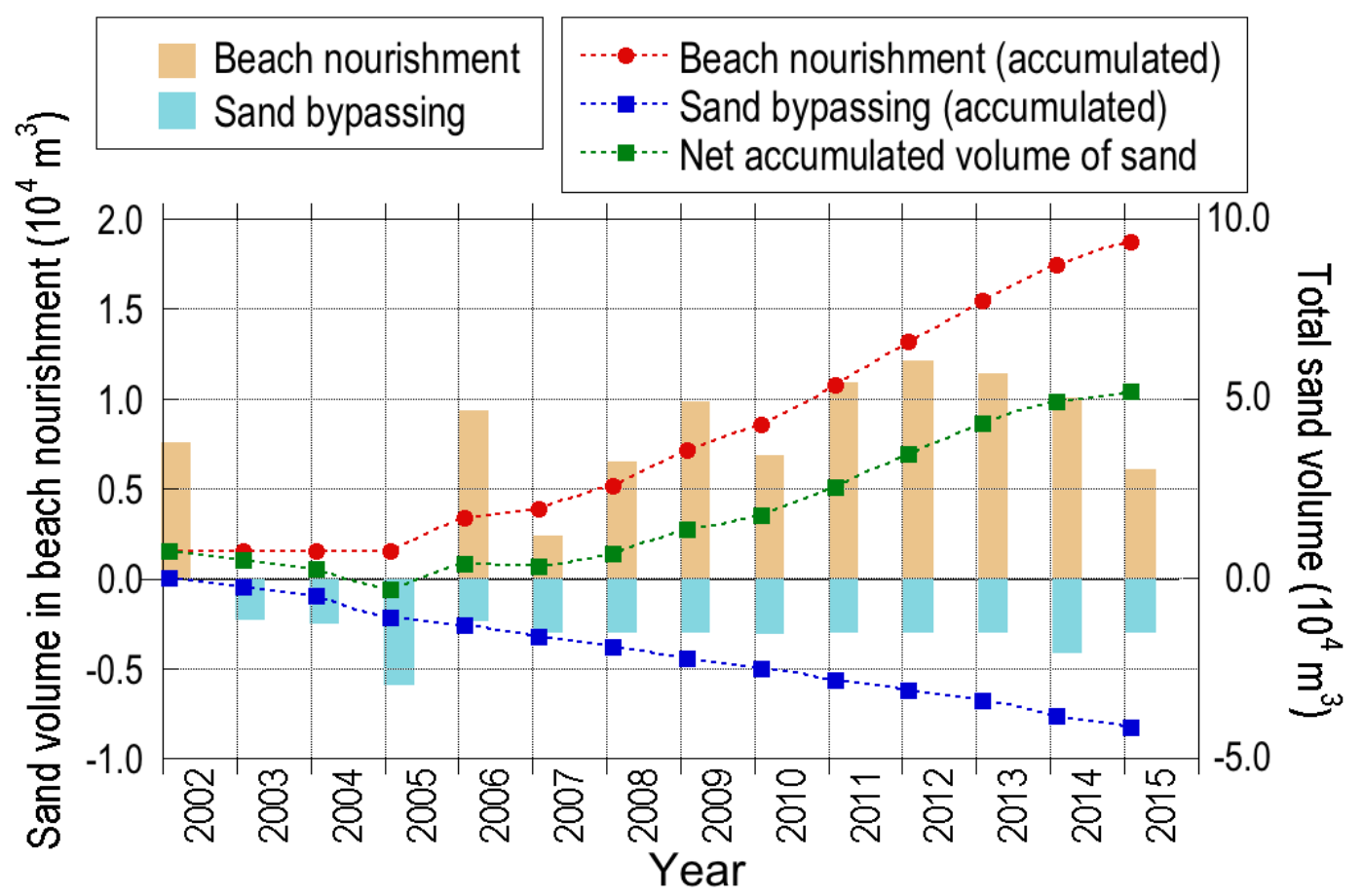

Figure 3. Change in sand volume for beach nourishment and sand bypassing since 2002 in Yanagishima area. 


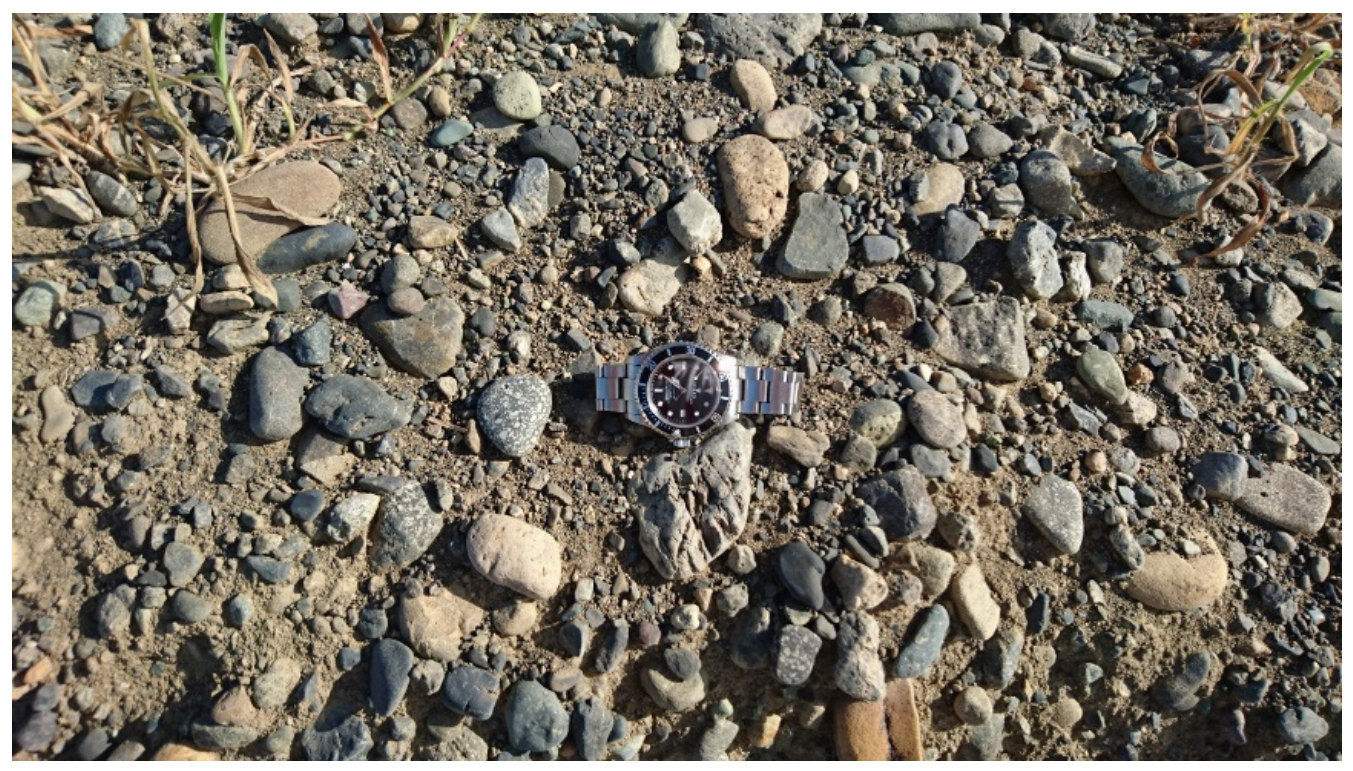

Figure 4. Material composed of gravel and sand for beach nourishment (August 16, 2016).

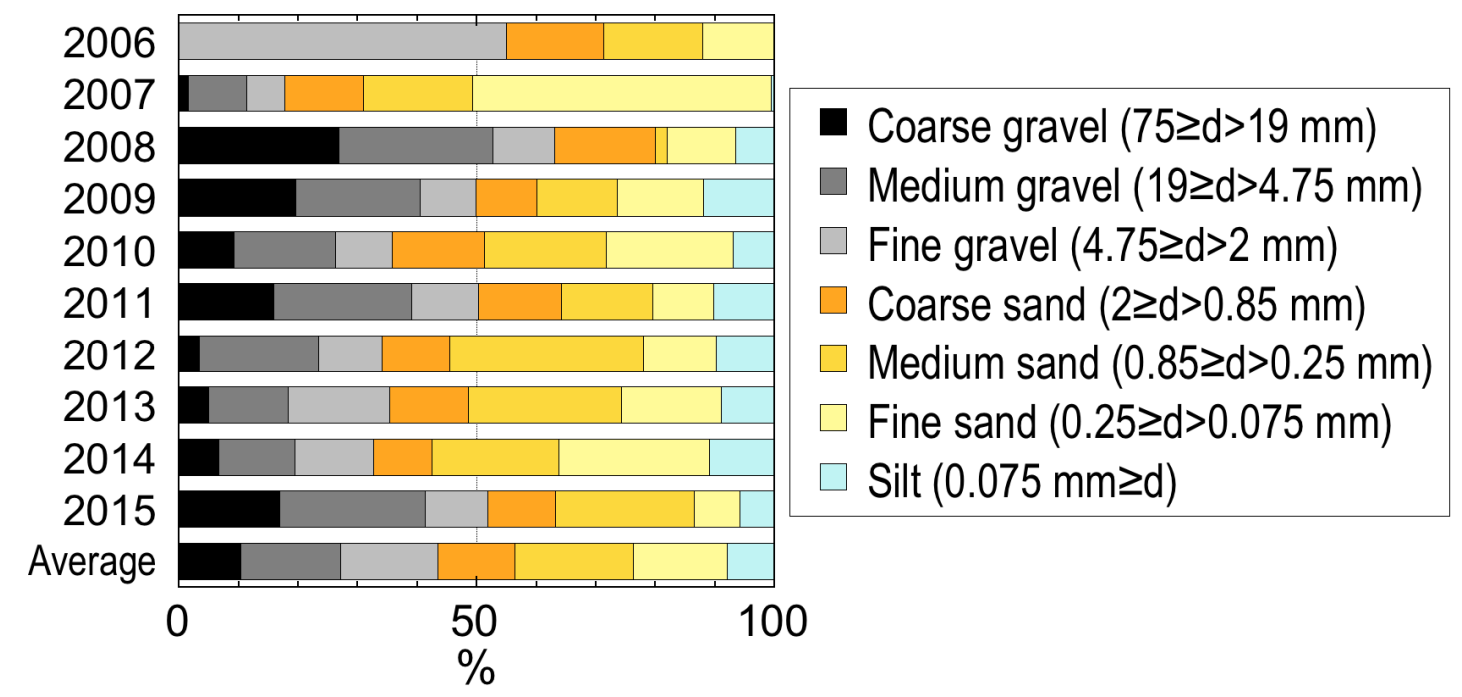

Figure 5. Grain size composition of beach nourishment material in Yanagishima area.

\section{RESULTS OF ANALYSIS OF BATHYMETRIC SURVEY DATA}

Topographic changes relative to the bathymetry in 2002 were analyzed, and the mechanism of sand deposition in the zone offshore of the fishing port was investigated. In particular, the relationship between the beach nourishment in the Yanagishima area and the sand deposition in the offshore zone was studied. In the analysis of the topographic changes, the study area was subdivided into six subareas, as shown in Fig. 6, where area $\mathrm{R}$ is the Sagami River mouth and E is the offshore area between Hirashima Rocks and Eboshi Rock offshore of the Chigasaki fishing port. 
(a) 2004

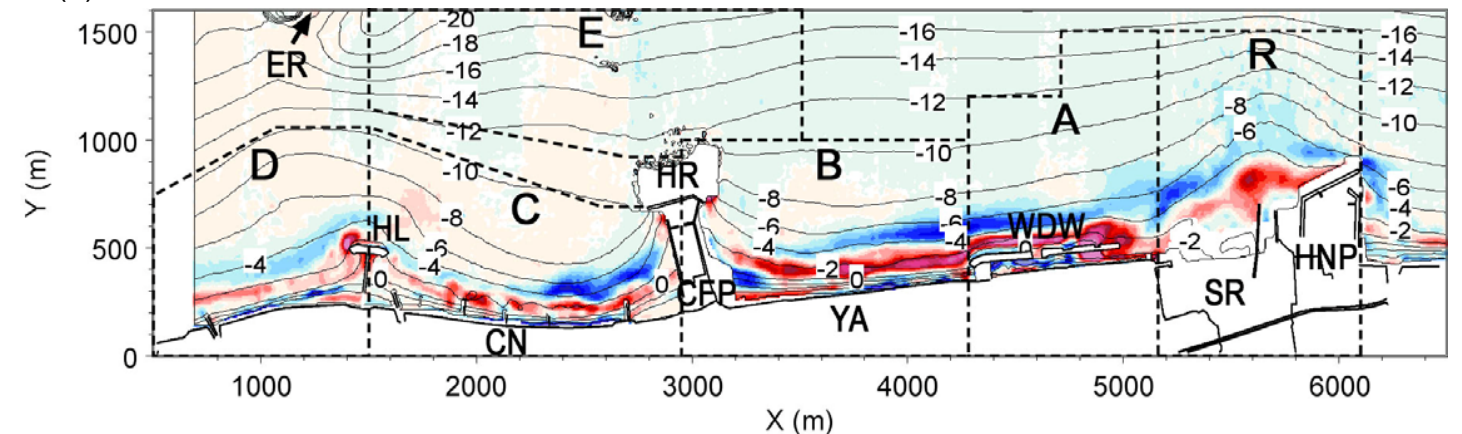

(b) 2008

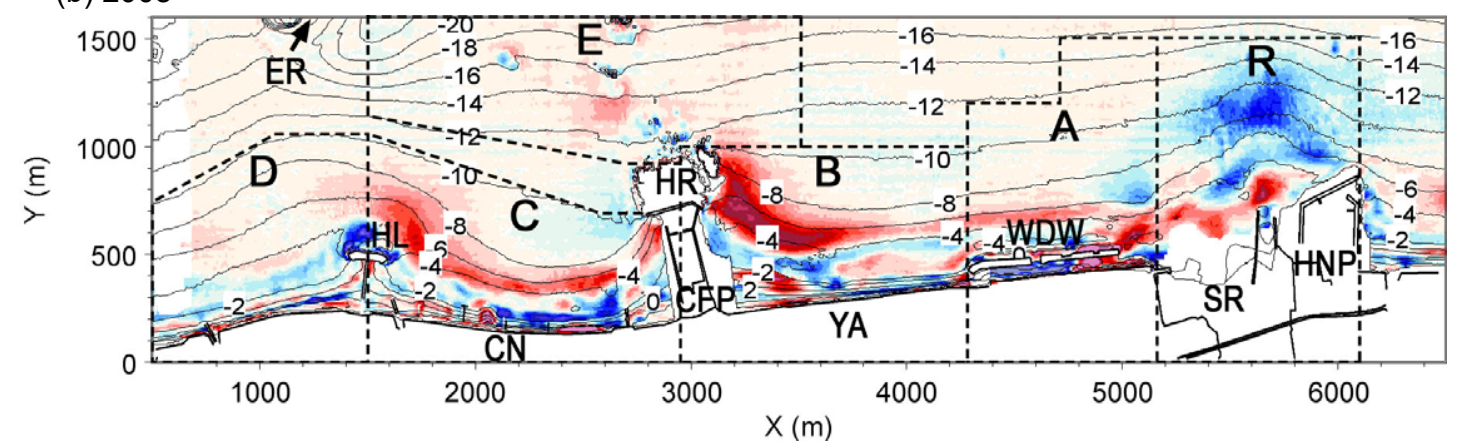

(c) 2011

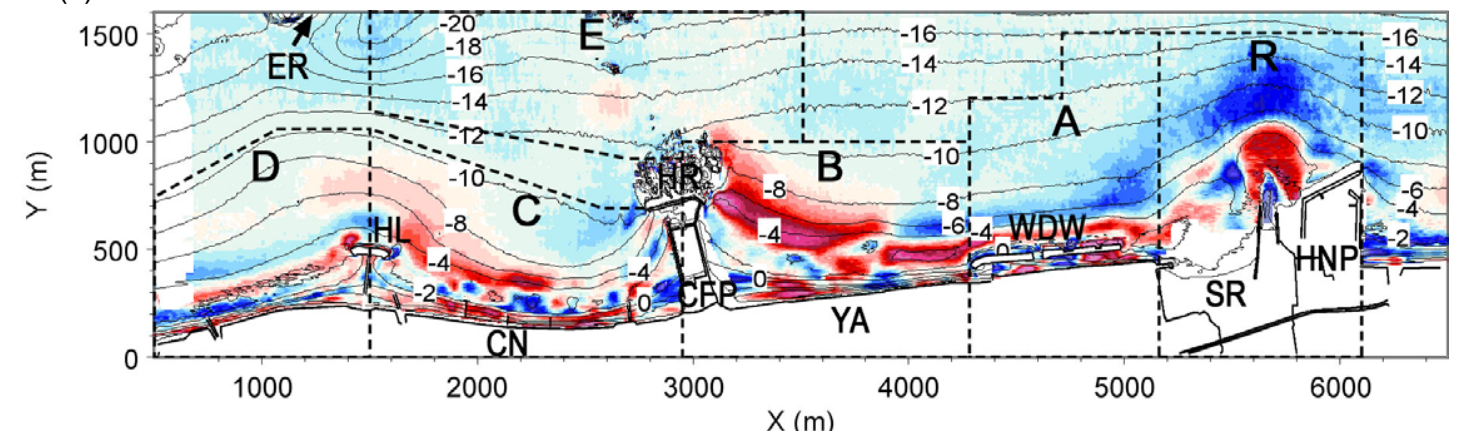

(d) 2015

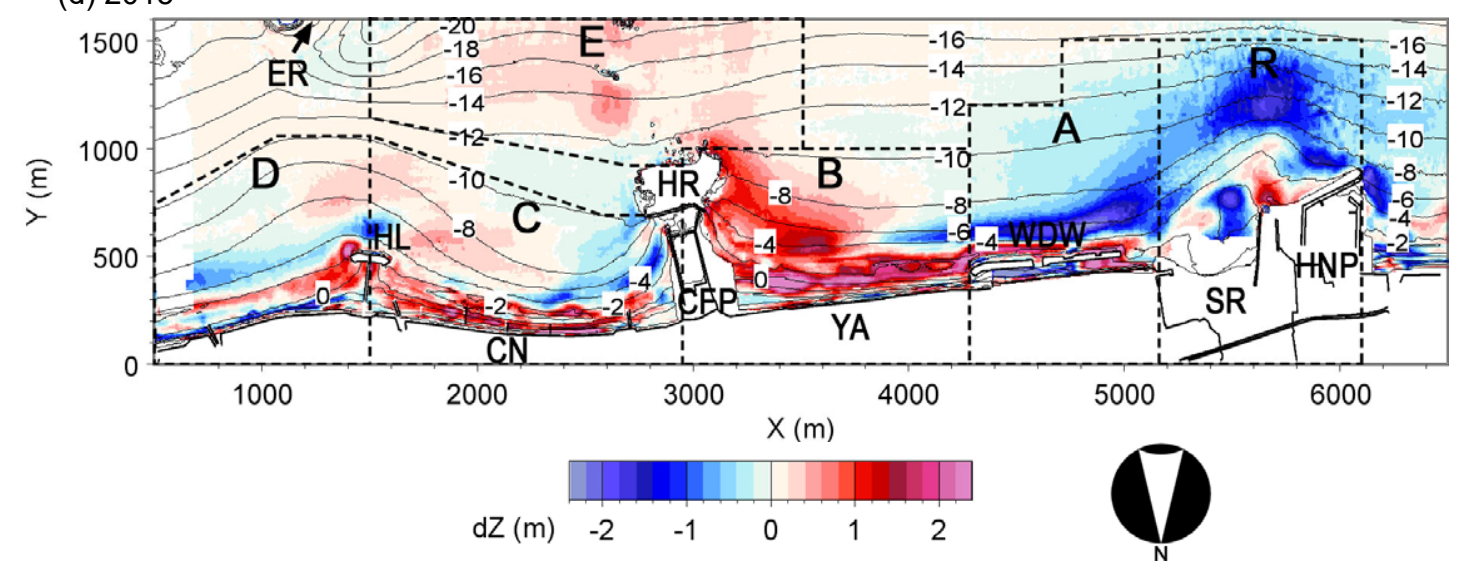

Figure 6. Bathymetries and bathymetric changes in 2004, 2008, 2011, and 2015 relative to bathymetry in 2002.

Topographic Changes in Entire Study Area

The seabed topographies measured between 2004 and 2015, and their changes relative to those measured in 2002 are shown in Fig. 6. In 2004, the offshore terrace of the Sagami River mouth in area $\mathrm{R}$ began to erode in the depth zone between -4 and $-8 \mathrm{~m}$, and a widespread area along the $6 \mathrm{~m}$ depth contour was erosive, whereas the area shallower than $-2 \mathrm{~m}$ was accretive in the entire area owing to the 
occurrence of shoreward sand transport. Although the west opening of the fishing port breakwater was closed by 2003, no significant changes were observed in the offshore area $\mathrm{E}$ up to 2004.

By 2008 , erosion in area $\mathrm{R}$ intensified further, and sand was markedly deposited between -4 and -8 $\mathrm{m}$ in area $\mathrm{B}$ west of the fishing port, and part of the sand deposition zone expanded offshore while turning around Hirashima Rocks located at the tip of the fishing port. Similarly, sand was deposited in the depth zone between -4 and $-8 \mathrm{~m}$ west of the Chigasaki artificial headland (HL). The sand deposition west of these structures suggests that predominant eastward longshore sand transport was blocked by the structures, and part of the longshore sand transport discharged into the offshore zone while turning around the tip of the structures. The fact that the areas east of the Chigasaki fishing port and the artificial headland are erosive also supports this.

By 2011, erosion not only in area $\mathrm{R}$ but also area A intensified further, even though erosion appeared in the overall offshore zone, which is assumed to be attributable to the low accuracy in the NMB survey in 2011. Then, up to 2015, severe erosion occurred in areas $\mathrm{R}$ and A. The maximum depth of the erosion zone offshore of the river mouth terrace reached $16 \mathrm{~m}$, and erosion became dominant offshore of the wave dissipating works at the Yanagishima area from 2011. In contrast, a large amount of sand was deposited in a wide area west of the Chigasaki fishing port, and the accretion zone expanded turning around the offshore end of Hirashima Rocks. In addition, a sand layer of over $0.2 \mathrm{~m}$ thickness was formed in a widespread area deeper than $-12 \mathrm{~m}$ in area $\mathrm{E}$, and the deposited sand layer was relatively thick behind offshore reefs located 450 and $650 \mathrm{~m}$ offshore of Hirashima Rocks. This sand deposition zone was observed only in area E, and no sand deposition zone was formed behind Eboshi Rock and its adjacent areas. Since area E is located southeast offshore of the sand deposition area immediately west of the Chigasaki fishing port and Hirashima Rocks, the eastward longshore current is assumed to be blocked by the fishing port and Hirashima Rocks, resulting in the formation of an oblique rip current directing southeastward, and fine sand was assumed to be transported offshore by this current. In this case, the water depth of the area with fine sand deposition is more than $-12 \mathrm{~m}$, so that a rip current was considered to develop under the incident condition of rough waves rather than normal waves.

\section{Changes in Sand Volume in Areas R, A, B, and E}

The changes in sand volume over time in areas R, A, B, and E relative to those in 2002 are shown in Fig. 7. In area R, the sand volume monotonically decreased from 2002 at a rate of $3.2 \times 10^{4} \mathrm{~m}^{3} / \mathrm{yr}$, and in area A immediately east of area $\mathrm{R}$, it remained constant until 2010, but then rapidly decreased at a rate of $4.0 \times 10^{4} \mathrm{~m}^{3} / \mathrm{yr}$. In contrast, the sand volume in areas B and E increased at the rates of $2.5 \times 10^{4}$ and $1.5 \times 10^{4} \mathrm{~m}^{3} / \mathrm{yr}$, respectively. Figure 8 shows the changes in sand volume in areas $\mathrm{R}+\mathrm{A}$ and $\mathrm{B}+\mathrm{E}$. The sand volume in area $\mathrm{R}+\mathrm{A}$ decreased by $7.3 \times 10^{5} \mathrm{~m}^{3}$ from 2005 , whereas it increased by $6.1 \times 10^{5} \mathrm{~m}^{3}$ in area $\mathrm{B}+\mathrm{E}$. A linear correlation was observed between the eroded volume of sand in area $\mathrm{R}+\mathrm{A}$ and the accreted volume in area $\mathrm{B}+\mathrm{E}$, although there were some scatters to some extent. It appears from this relationship that the volume of sand deposited upcoast of the fishing port is smaller than that eroded from the upcoast, suggesting that part of the sand eroded from area $\mathrm{R}+\mathrm{A}$ had been transported toward not only area B but also area E. The rate of increase in sand volume in area B, as shown in Fig. 7(c), decreased to $2.3 \times 10^{4} \mathrm{~m}^{3} / \mathrm{yr}$, when the contribution to the increase in sand volume by beach nourishment in area B was corrected. Thus, longshore sand transport blocked by the fishing port breakwater was estimated to be $2.3 \times 10^{4} \mathrm{~m}^{3} / \mathrm{yr}$.

Figure 10 shows the volume change in each year in area $\mathrm{C}$ downcoast of the Chigasaki fishing port, the annual volume of beach nourishment in the same area, the cummulative change in sand volume relative to that in 2002, and cummulative volume of beach nourishment. Approximately $3.0 \times 10^{4} \mathrm{~m}^{3}$ of sand has been nourished every year in area $\mathrm{C}$, resulting in an increasing rate of the cummulative sand volume by $1.6 \times 10^{4} \mathrm{~m}^{3} / \mathrm{yr}$ in area C. However, this rate is smaller than the annual rate of beach nourishment of $3.0 \times 10^{4} \mathrm{~m}^{3}$ by $1.4 \times 10^{4} \mathrm{~m}^{3} / \mathrm{yr}$. This means that the rate of eastward sand transport turning around the tip of HL has increased over the initially expected rate of $5 \times 10^{3} \mathrm{~m}^{3} / \mathrm{yr}$ with the successive shoreline advance as a result of the beach nourishment on the Chigasaki-naka coast.

Figure 11 shows the change in sand volume in area D east of $\mathrm{HL}$ relative to that in 2002 . The entire volume of sand in area $\mathrm{D}$ has remained constant, even though beach nourishment has been carried out at a rate of $8 \times 10^{3} \mathrm{~m}^{3} / \mathrm{yr}$ in area $\mathrm{D}$, and sand flows into area $\mathrm{D}$ at a rate of $1.4 \times 10^{4} \mathrm{~m}^{3} / \mathrm{yr}$ from area $\mathrm{C}$ turning around the tip of the HL. Accordingly, it is concluded that sand in area D is transported away at a rate of $2.2 \times 10^{4} \mathrm{~m}^{3} / \mathrm{yr}$ by eastward longshore sand transport at present. 
(a) Area R

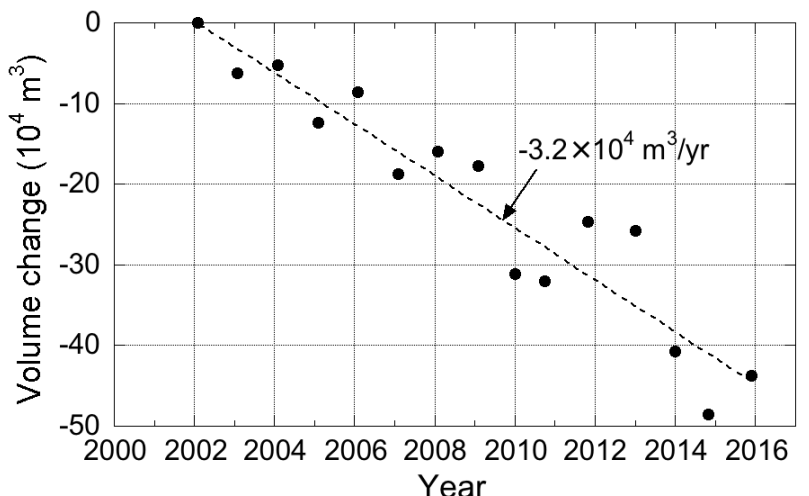

(b) Area A

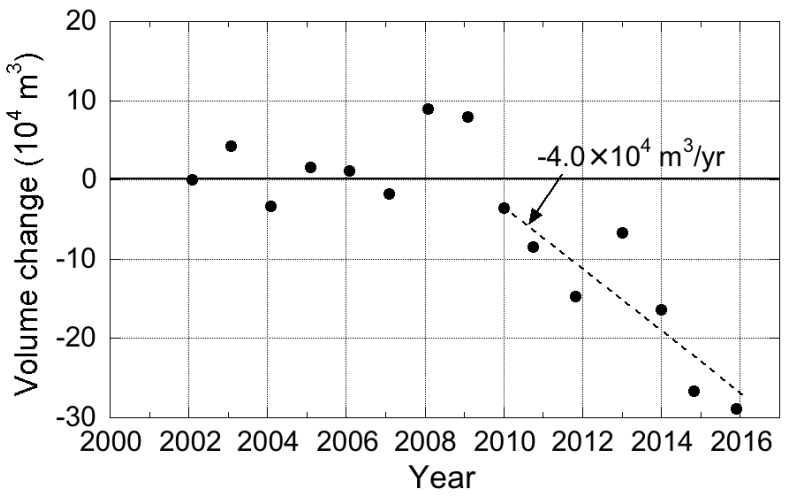

(c) Area B

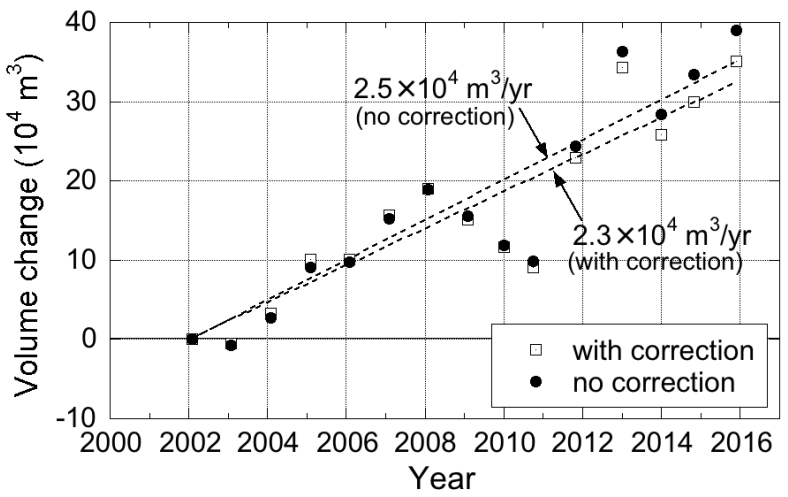

(d) Area E

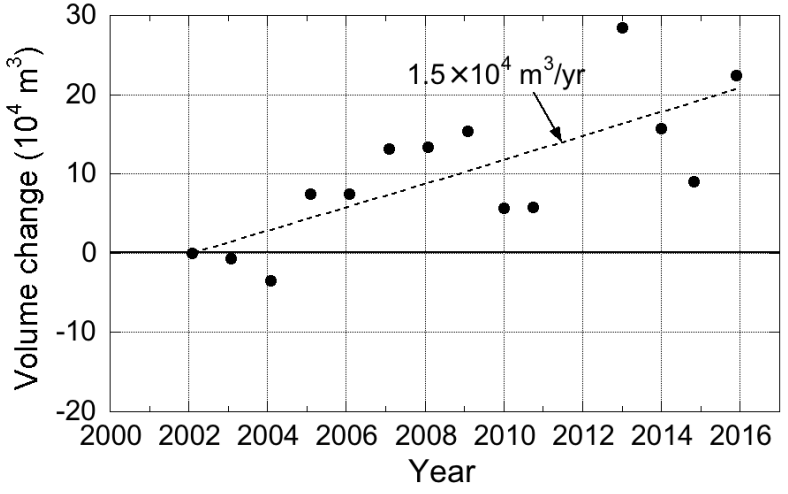

Figure 7. Change in sand volume in areas $R, A, B$, and $E$. 


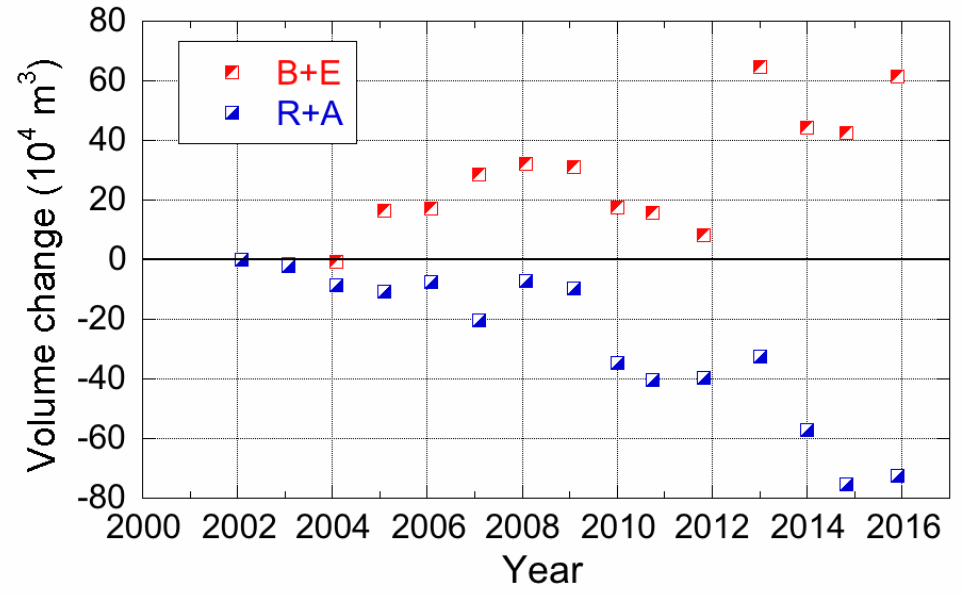

Figure 8. Change in total volume of sand in areas $R+A$ and $B+E$.

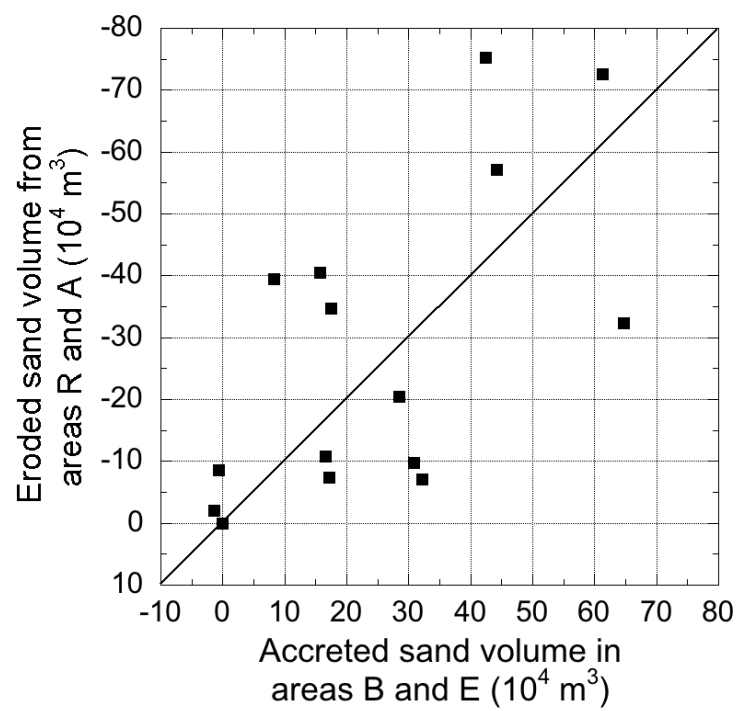

Figure 9. Relationship between sand volume eroded in area $R+A$ and that accreted in area $B+E$.

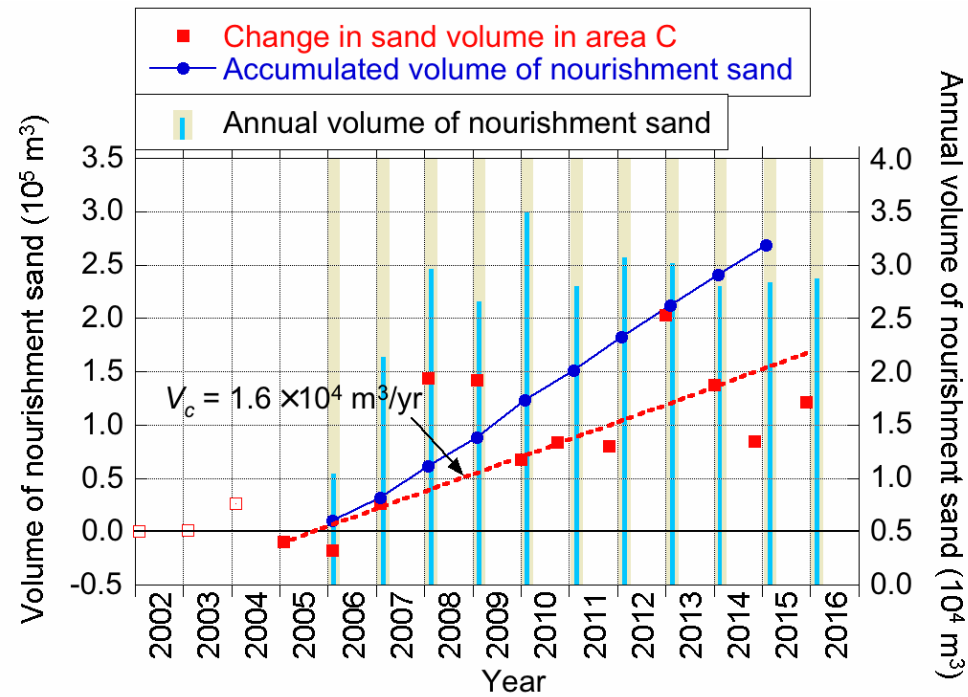

Figure 10. Change in sand volume in area $C$ relative to that in 2002 and annual volume of nourishment sand. 


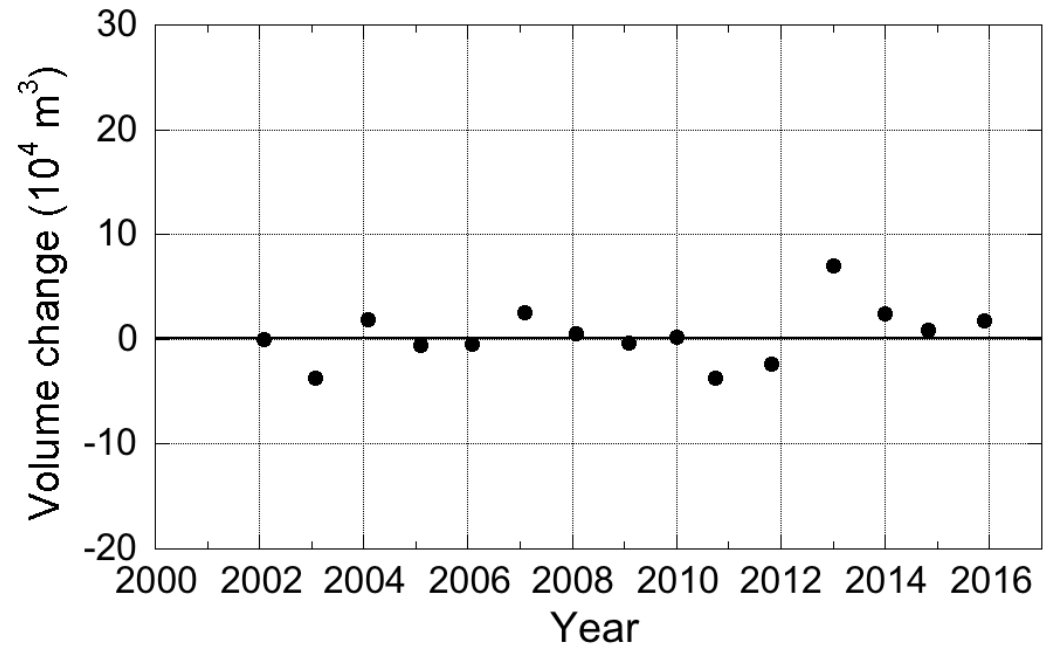

Figure 11. Change in sand volume in area D relative to that in 2002.

\section{Grain Size Composition of Seabed Material in Area E and along Transect Nos. 3 and 5}

Figure 12 shows the composition of the seabed material at Sts. 1-4 with water depths of 9, 12, 15, and $22 \mathrm{~m}$, respectively, in area E offshore of the Chigasaki fishing port, as shown in Fig. 1(b). The seabed material in area $\mathrm{E}$ is mainly composed of fine sand, and the silt content increases with water depth with a maximum of $20.5 \%$. The average composition at Sts. $1-4$ was $0.3 \%$ coarse sand, $5.3 \%$ medium-size sand, $84.4 \%$ fine sand, and $9.9 \%$ silt, mostly composed of fine sand and silt. This grain size distribution in the offshore zone well contrasts to that near the shoreline. Figure 13 shows the change in longitudinal profiles along transect Nos. 3 and 5, together with the depth distribution of the composition of the seabed material in the nearshore zone. The seabed material along these transects is mainly composed of medium-size and fine sand with the medium-size sand as the predominant component, which markedly differs from those measured at Sts. 1-4 in area E, as shown in Fig. 12.

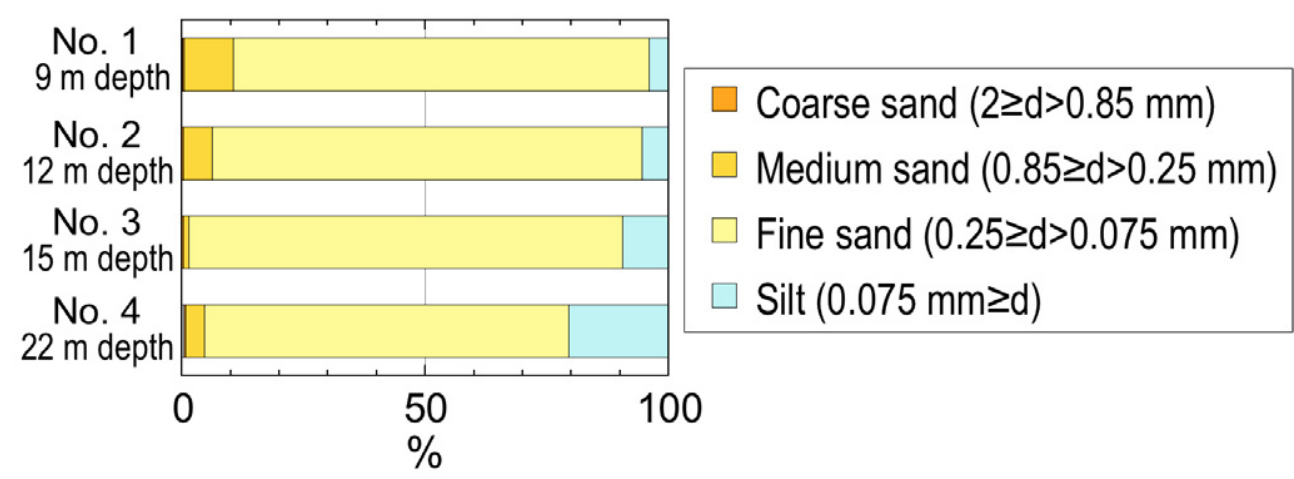

Figure 12. Grain size composition of bed material in offshore deposition zone measured on July 6, 2016. 
(a) Transect No. 3

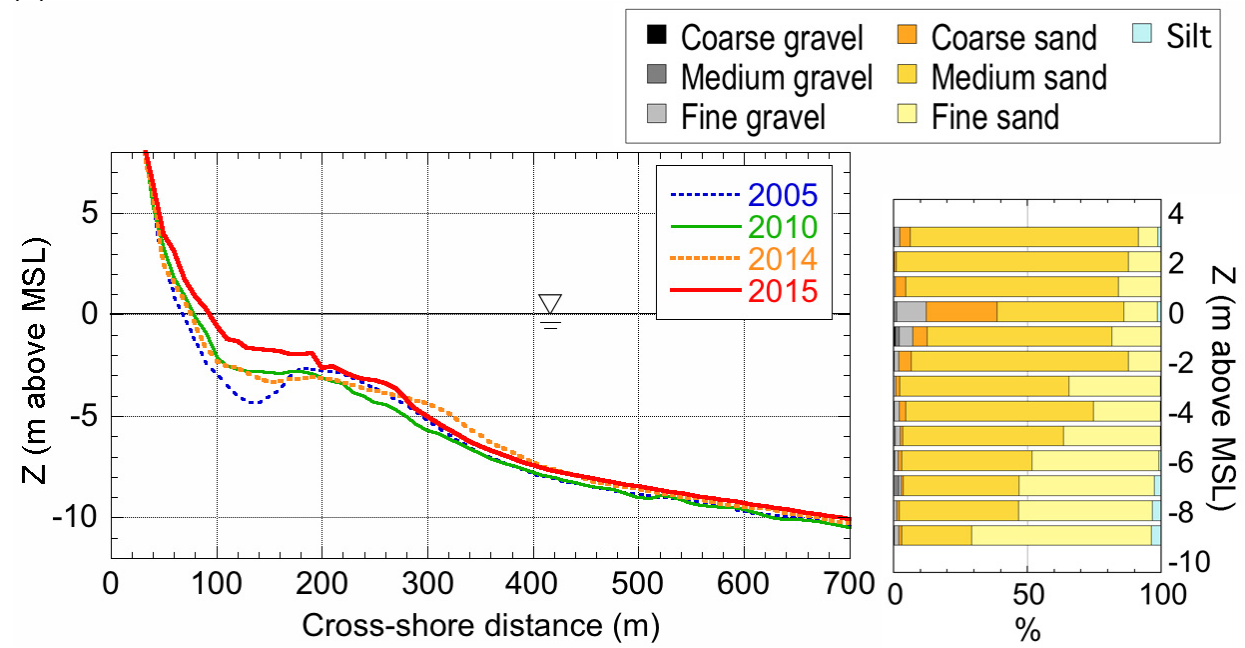

(b) Transect No. 5
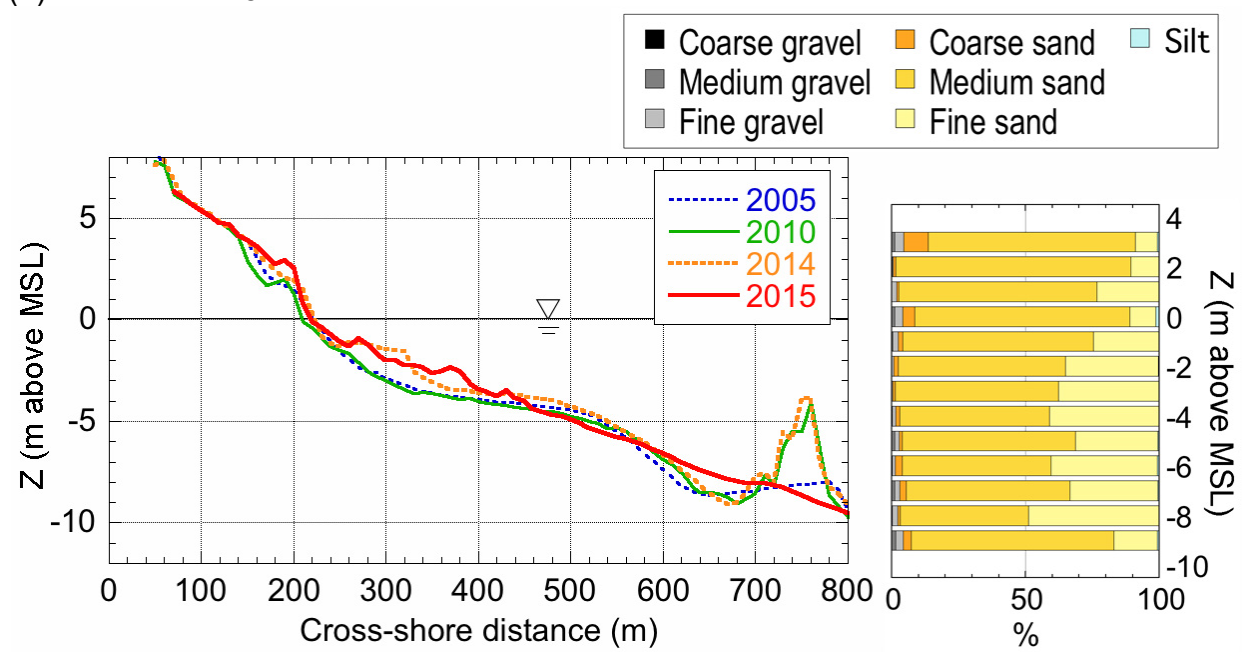

Figure 13. Longitudinal profiles and depth distribution of grain size composition along transect Nos. 3 and 5 (January, 2016).

\section{NUMERICAL SIMULATION OF NEARSHORE CURRENT}

To investigate the mechanism of sand deposition in the offshore zone, a numerical simulation of nearshore current was carried out using the method of Horikawa et al. (1988), while adopting the calculation domain shown in Fig. 14. The bathymetry shown in Fig. 14 was produced from the combination of the bathymetry (Fig. 1(b)) measured in 2016 and the sounding map of the offshore seabed produced in 1983 by the Japan Maritime Safety Agency. As the wave conditions, the data observed since 1980 at the Hiratsuka wave observatory with the depth of $20 \mathrm{~m}$ west of the Sagami River mouth, as shown in Fig. 14, were used. The calculation domain for the numerical simulation of the nearshore current has a $8.5 \mathrm{~km}$ alongshore length and $2.6 \mathrm{~km}$ width (Fig. 14). For incident waves, the storm wave condition with a significant wave height of $3.44 \mathrm{~m}$ and a wave period of $14.2 \mathrm{~s}$ with the probability of occurrence of several times a year (upper $0.1 \%$ ) was employed on the basis of wave observation data that have been measured at the Hiratsuka wave observatory since 1988 .

Figure 15 shows the distribution of wave direction on the basis of the wave observation data that have been recorded since 1988. Easterly waves prevail between spring and autumn, and westerly waves in winter, resulting in the occurrence of two peaks on both sides of the energy mean wave direction of $\mathrm{S} 8^{\circ} \mathrm{E}$. Because eastward longshore sand transport is mainly caused by the predominant waves incident from the SW, wave directions from $\mathrm{S}, \mathrm{S} 10^{\circ} \mathrm{W}$, and $\mathrm{S} 20^{\circ} \mathrm{W}$ were assumed in Cases 1, 2, and 3, respectively. Wave directions at the Hiratsuka wave observatory corresponding to the wave directions of $\mathrm{S}, \mathrm{S} 10^{\circ} \mathrm{W}$, and $\mathrm{S} 20^{\circ} \mathrm{W}$ assumed in Cases $1-3$ are denoted by signs of $\mathrm{S} 0.2^{\circ} \mathrm{E}$ (Case 1 ), $\mathrm{S} 6.5^{\circ} \mathrm{W}$ 
(Case 2), and $\mathrm{S} 12.8^{\circ} \mathrm{W}$ (Case 3) in Fig. 15, respectively. The other calculation conditions are shown in Table 1.

The results of numerical simulation in Cases 1-3 are shown in Fig. 16. In each case, an eastward strong longshore current develops along the terrace offshore of the Sagami River mouth. This well explained the severe erosion in these areas, as shown in Fig. 6. A rip current was generated west of the Chigasaki fishing port with a rip head in a depth zone between -12 and $-18 \mathrm{~m}$ because the eastward longshore current was blocked by the fishing port breakwater. The velocity of th rip current decreases with increasing water depth, and the rip current changes to eastward longshore current in the depth zone between -12 and $-18 \mathrm{~m}$ in the offshore zone. This rip current moved closer to the Chigasaki fishing port given the larger westerly wave incidence. In particular, when waves were incident from $\mathrm{N} 200^{\circ} \mathrm{E}$, the eastward current that developed west of the Chigasaki fishing port was blocked by the reversed, westward offshore current (Fig. 16). Fine sediment transported by the eastward longshore current from area $\mathrm{R}+\mathrm{A}$ can be deposited in the offshore zone because of this decrease in velocity. On the other hand, between Eboshi Rock and the Chigasaki fishing port, a couple of circulating currents develop, and their intensities decrease with increasing incident angle between $\mathrm{N} 180^{\circ} \mathrm{E}$ and $\mathrm{N} 200^{\circ} \mathrm{E}$, and conversely, the intensity of the clockwise circulating current offshore of the HL increases. In particular, when waves are incident from $\mathrm{N} 200^{\circ} \mathrm{E}$, as shown in Fig. 16(c), the eastward longshore current is effectively blocked.

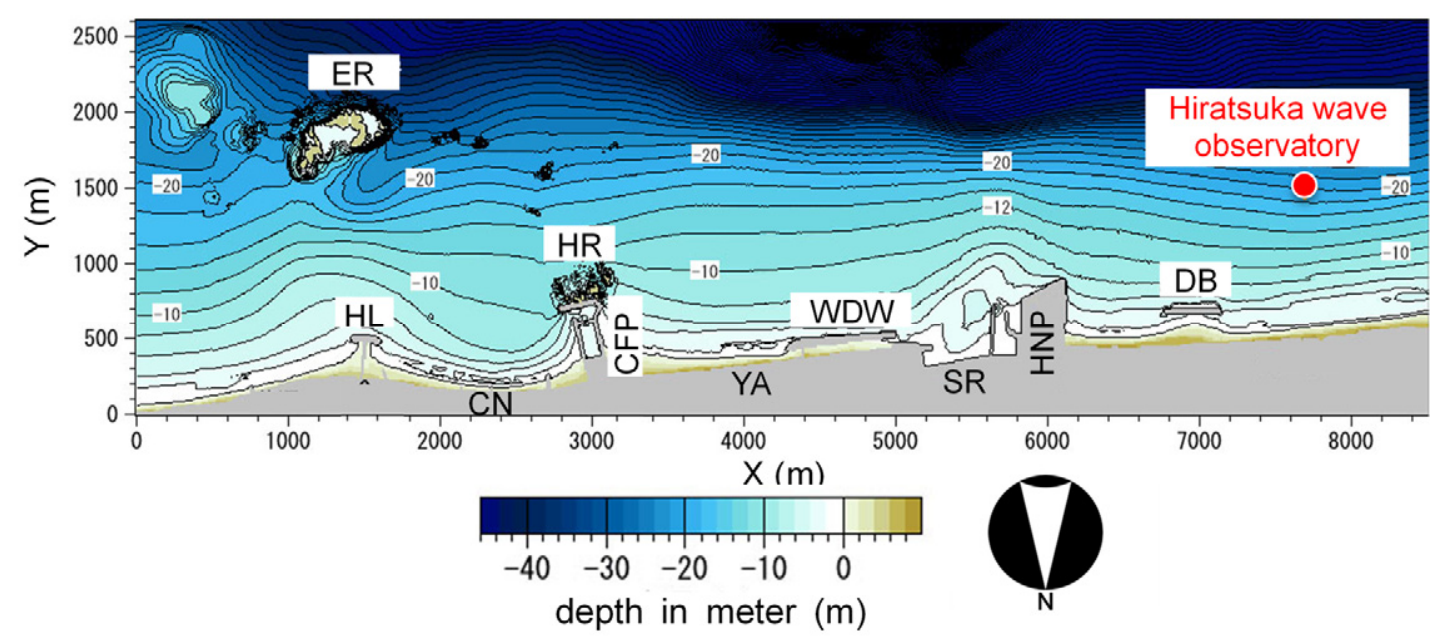

Figure 14. Calculation domain of nearshore currents and location of Hiratsuka wave observatory (water depth: $20 \mathrm{~m}$ ).

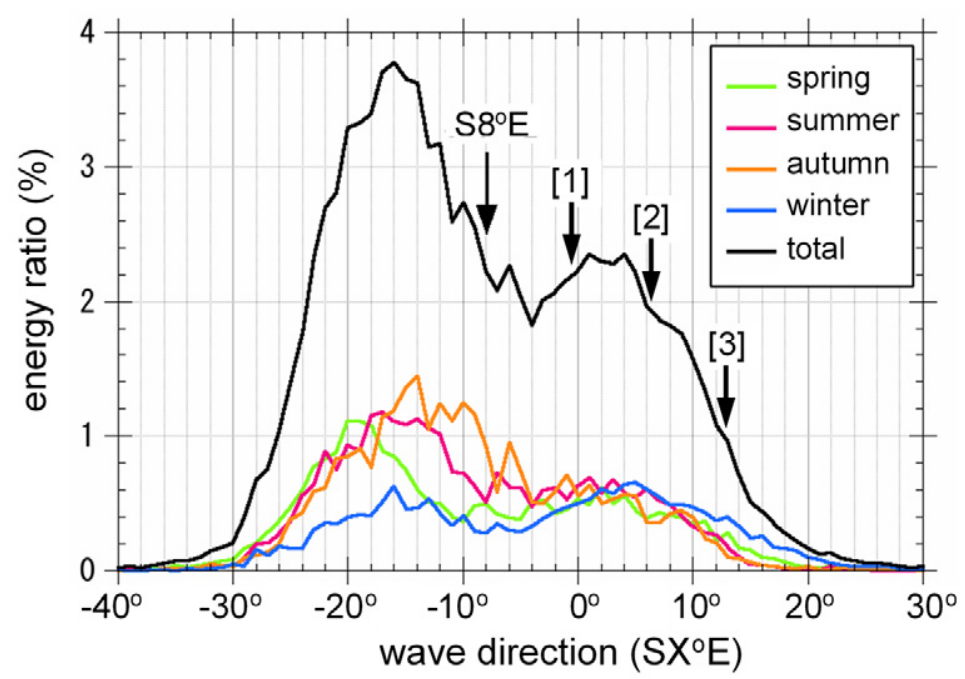

Figure 15. Probability of occurrence of wave direction measured between 1988 and 2015 at Hiratsuka wave observatory. 


\begin{tabular}{|c|c|}
\hline Calculation domain & $8.5 \mathrm{~km}$ alongshore and $2.6 \mathrm{~km}$ cross-shore \\
\hline Bathymetry & $\begin{array}{l}\text { Topography in } 2016+\text { sounding map of offshore seabed produced in } 1983 \text { by } \\
\text { Japan Maritime Agency }\end{array}$ \\
\hline Wave conditions & $\begin{array}{l}\text { Incident waves: } H_{1}=3.44 \mathrm{~m} \text { and } T=14.2 \mathrm{~s} \\
\text { Storm wave condition with the probability of occurrence of several times a year } \\
\text { (upper } 0.1 \% \text { ) was employed on the basis of wave observation data measured at } \\
\text { Hiratsuka wave observatory between } 1988 \text { and } 2015 \text {. }\end{array}$ \\
\hline Sea level & $0.0 \mathrm{~m}$ above $\mathrm{MSL}$ \\
\hline Calculation cases & Case 1: wave direction $\mathrm{N} 180^{\circ} \mathrm{E}$, Case 2: $\mathrm{N} 190^{\circ} \mathrm{E}$, Case 3: N200 $\mathrm{E}$ \\
\hline Mesh size & $\Delta x=\Delta y=10 \mathrm{~m}$ \\
\hline $\begin{array}{l}\text { Calculation } \\
\text { of wave field }\end{array}$ & $\begin{array}{l}\text { - Energy balance equation (Mase 2001) } \\
\text { - Term of wave dissipation due to wave breaking; Dally et al. (1984) model } \\
\text { - Wave spectrum of incident waves; directional wave spectrum density obtained by } \\
\text { Goda (1985) } \\
\text { - Total number of frequency components } N_{\mathrm{F}}=3 \text {, and number of directional } \\
\text { subdivisions } N_{\theta}=16 \\
\text { - Directional spreading parameter } S_{\max }=25 \\
\text { - Coefficients of wave breaking } K=0.17 \text { and } \Gamma=0.35 \\
\text { - Imaginary depth between minimum depth } h_{\circ} \text { and berm height } h_{\mathrm{R}} ; h_{\circ}=1 \mathrm{~m} \\
\text { - Wave energy }=0 \text { where } Z \geq h_{\mathrm{R}}\end{array}$ \\
\hline $\begin{array}{l}\text { Calculation } \\
\text { of nearshore current }\end{array}$ & $\begin{array}{l}\text { - Two-dimensional shallow water momentum equation and continuity equation } \\
\text { (Horikawa et al. 1988) } \\
\text { - Explicit finite-difference method } \\
\text { - Friction coefficient } C_{\mathrm{f}}=0.01 \\
\text { - Lateral diffusion coefficient } N=0.5 \text { (Larson and Kraus 1991) } \\
\text { - Minimum water depth } h_{\min }=1 \mathrm{~m} \\
\text { - Time interval } \Delta t=0.2 \mathrm{~s} \\
\text { - Duration of calculation } 20,000 \text { steps }\end{array}$ \\
\hline
\end{tabular}

\section{DISCUSSION}

The expansion of the sand deposition zone in area E over time was considered to be due to the discharge of part of the sand carried by eastward longshore sand transport turning around the Chigasaki fishing port breakwater. Sand transported by eastward longshore sand transport was assumed to be mainly supplied from the erosion of the river mouth terrace, but there is a possibility that part of the sand was supplied from the Yanagishima area where beach nourishment has been carried out. The entire volume of sand in beach nourishment at Yanagishima area was $9.4 \times 10^{4} \mathrm{~m}^{3}$ between 2002 and 2015 at a rate of $5.0 \times 10^{3} \mathrm{~m}^{3} / \mathrm{yr}$. Therefore, the total amount of the fine material, the grain size of which is smaller than that of fine sand, contained in the beach nourishment in the Yanagishima area decreased to $2.2 \times 10^{4} \mathrm{~m}^{3}$ at an increasing rate of $1.2 \times 10^{3} \mathrm{~m}^{3} / \mathrm{yr}$, because the fine material was $23.8 \%$ of the beach nourishment (fine sand: $15.8 \%$ and silt: $8 \%$ ), as shown in Fig. 5 . This is only $8 \%$ of the rate of deposition of $1.5 \times 10^{4} \mathrm{~m}^{3} / \mathrm{yr}$ in area E, where the primary constituents of the seabed material deposited are $84.4 \%$ fine sand and $9.9 \%$ silt, as shown in Fig. 12, even though the entire volume of the material smaller than fine sand contained in the nourishment material is discharged. This clearly explains that the fine material deposited in the offshore zone did not originate from the nourishment material but was transported from the west. Finally, it was concluded that the effect of the beach nourishment on the deposition of sediment offshore of the fishing port was negligible, and none of the nourishment sand composed of coarse grains in the Yanagishima area was transported offshore. The fine material in the offshore zone mainly originated from the erosion of the river mouth terrace in area $\mathrm{R}$.

\section{CONCLUSIONS}

Part of the nourishment sand in the Yanagishima area of the Shonan coast has been considered to be transported offshore, devaluing the effect of beach nourishment. Topographic changes that have occurred since the beach nourishment were, therefore, investigated using the Narrow Multi-Beam survey data that have been collected since 2002. From the analysis of the sand volume and grain size composition in the subareas, it was concluded that the effect of the beach nourishment on the deposition of fine sediment in the offshore zone was negligible, and that the fine material in the offshore zone mainly originated from the erosion of the river mouth terrace. In the investigation of beach changes including offshore areas after beach nourishment, not only the investigation of the volumetric changes but also the changes in grain size composition is important. Finally, the local 
fishermen's fear that the damage to the offshore fishing ground rich in kelp and abalone owing to the coverage of the exposed rocks by nourishment material was cleared. Also, we learned that not only the investigation of the volumetric changes but also the changes in grain size composition is important in the investigation of beach changes after beach nourishment.

(a) Case 1: wave direction of $180^{\circ} \mathrm{E}$

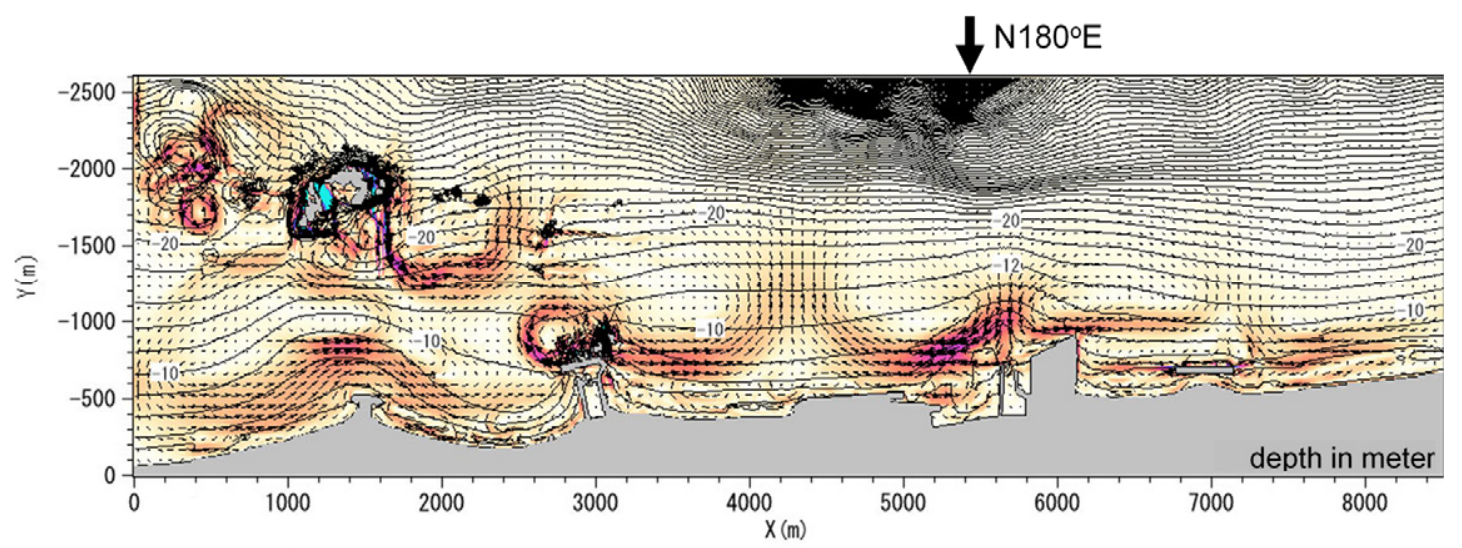

(b) Case 2: wave direction of $\mathrm{N} 190^{\circ} \mathrm{E}$

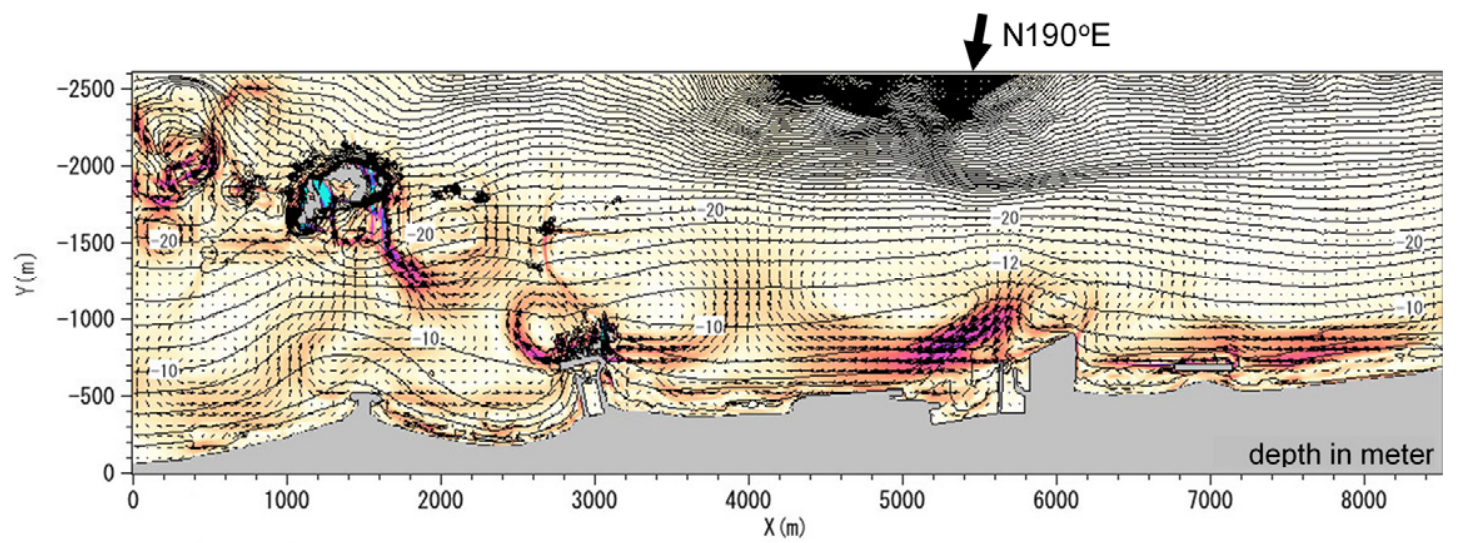

(c) Case 3: wave direction of $\mathrm{N} 200^{\circ} \mathrm{E}$

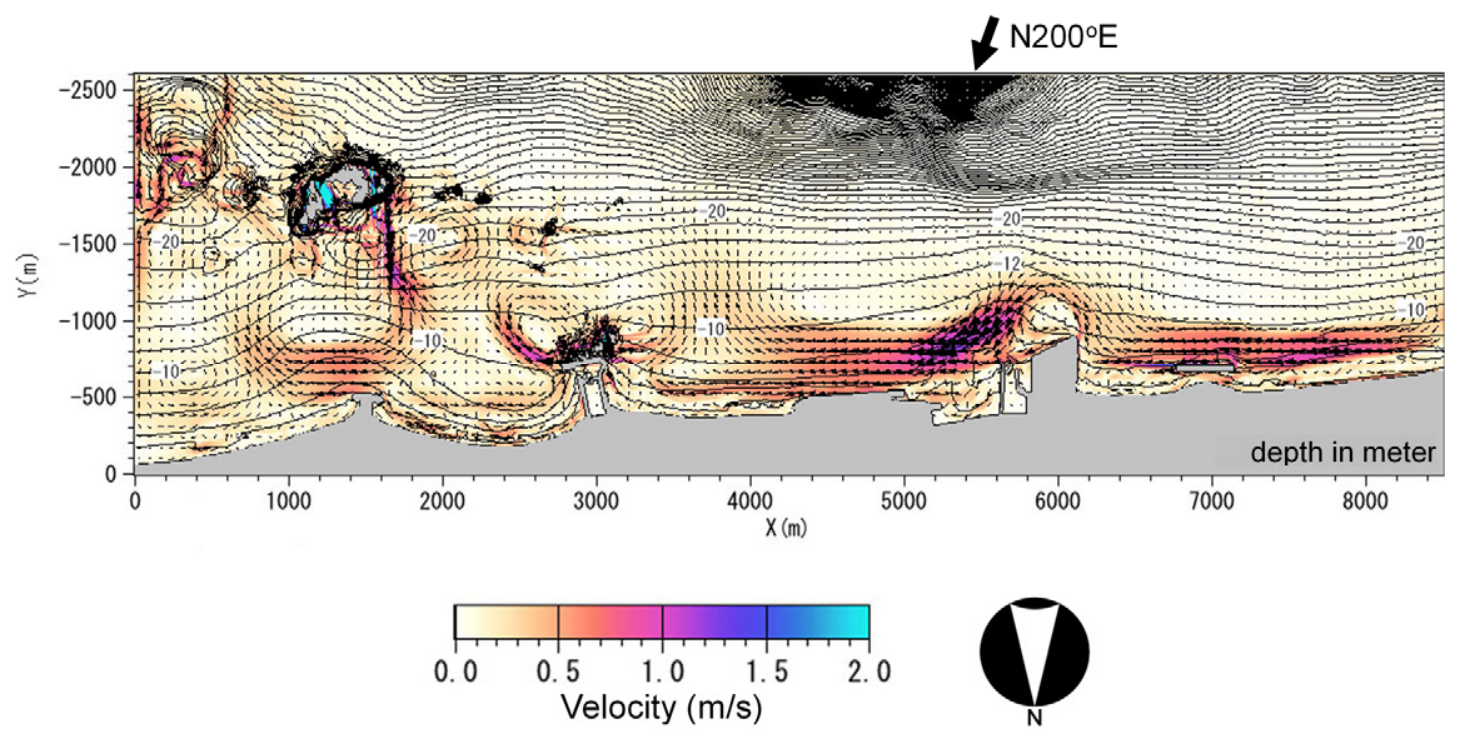

Figure 16. Calculated nearshore currents given wave direction of $\mathrm{S}^{\circ} .2^{\circ} \mathrm{E}, \mathrm{S} 6.5^{\circ} \mathrm{W}$, and $\mathrm{S} 12.8^{\circ} \mathrm{W}$. 


\section{REFERENCES}

Dally, W.R., R.G. Dean, R.A. Dalrymple. 1984. A model for breaker decay on beaches, Proceedings of $19^{\text {th }}$ International Conference on Coastal Engineering, ASCE, 82-97. https://journals.tdl.org/icce/index.php/icce/article/view/3787/3470

Goda, Y. 1985. Random Seas and Design of Maritime Structures, University of Tokyo Press, Tokyo, $323 \mathrm{p}$.

Horikawa, K. ed. 1988. Nearshore Dynamics and Coastal Processes, University of Tokyo Press, Tokyo, $522 \mathrm{p}$.

Ishikawa, T., T. Uda, T. San-nami, G. Aoshima, and A. Yoshioka. 2009. Comprehensive management of sand considering grain size on Shonan coast, Proceedings of Coastal Dynamics 2009, Paper No. $71,1-12$.

Ishikawa, T., T. Uda, T. San-nami, and J. Hosokawa. 2013. Verification of shore protection effect of beach nourishment on Chigasaki coast, Asian and Pacific Coasts 2013, Proceedings of $7^{\text {th }}$ International Conference, 1-8.

Larson, M., and N.C. Kraus. 1991. Numerical model of longshore current for bar and trough beaches, $J$. Waterway Port Coastal and Ocean Engineering, ASCE, Vol. 117, No. 4, 326-347.

Mase, H. 2001. Multidirectional random wave transformation model based on energy balance equation, Coastal Eng. J., JSCE, Vol. 43, No. 4, 317-337. 